\title{
Influence of natural and climatic factors on the organization of construction
}

\author{
Marat Kuzhin $^{1 *}$, Ekaterina Chepik ${ }^{1}$, Angelina Baranova ${ }^{1}$ \\ ${ }^{1}$ Moscow State University of Civil Engineering, 26 Yaroslavskoe sh., Moscow, 129337, Russia
}

\begin{abstract}
In this research the influence of natural and climatic conditions on the organization of construction production are examined. Our purpose was to identify the nature of the dependence of the duration of construction work on natural and climatic factors. The analysis of normative and technical documentation in terms of accounting for the influence of natural and climatic factors was made. The system of estimation of influence of natural conditions on preparatory, ground, facade, roofing works, and also the appliance of monolithic structures, installation of prefabricated ferroconcrete items, and on works - implementation of internal finishing is offered. It was estimated, that the norms of construction production take into account a certain number of natural and climatic factors affecting the performance of work, but most of these factors have not yet been given in the normative and technical documentation. It is necessary to study this issue more comprehensively and to establish exact dependences on natural and climatic conditions, which will allow to quantify these factors already while calculating. This is necessary to compile more accurate calendar plans and schedules of production of works, as close as possible to real conditions. The study of this issue is one of the most important issues in the design of construction production. With insufficient consideration of these factors, the final actual figures are very different from the projected ones, which also lead to an increase in the cost of construction and installation work and the duration of their implementation. Taking into consideration the influence of natural and climatic factors will allow planning construction production more accurate.
\end{abstract}

\section{Introduction}

The construction industry is a type of activity that is very much influenced by external influences. Construction planning is based on calculations of construction work parameters based on their performance under normal conditions. But often the actual conditions of work differ significantly from the planned ones. As a result, actual technical and economic values "change a lot". In order to ensure "reliability" of the organizational and technical solution of their parameters, it is necessary to perform an analysis of the conditions of production of works. Natural and climatic factors are one of the most important conditions affecting the parameters of production of works.

\footnotetext{
${ }^{*}$ Corresponding author: kuzhinmarat@yandex.ru
} 


\section{Materials and methods}

Productivity is one of the most important parameters, and is the main criterion for measuring work activity. In construction, the productivity of workers is determined by their production, that is, the amount of construction products issued per unit of time (usually in an hour or a work shift). The level of labour productivity can also be characterized by the cost of working time per unit of construction products, which are regulated by official time standards and prices published in the form of handbooks. Uniform standards and prices for construction, installation and repair and construction works - USaP. Precisely in this document all sides of the production of the necessary works are maximally covered, the conditions for their implementation are signed, and all possible factors and their direct impact on the productivity of works are indicated.

The average coefficients for the time standards for winter works are also given in the USaP. So, these coefficients provide the influence on the productivity of such factors as, the tightness of movement due to warm, usually bulky, clothes, such as - low visibility. There are difficulties because of filling with snow and ice of materials, tools, constructions, additional time for cleaning is required, technological processes are strongly complicated.

It should be borne in mind that in the production of works on wind-open places, the average coefficients in especially windy days are correspondingly increased: In the Arctic and mountain-hilly areas by 15-20 per cent during repair and construction works; in all areas, as well as the Arctic and mountain-hilly areas by 15 per cent during installation and climbing works.

If necessary, according to the terms of production of simultaneous application to the time standards of several coefficients specified in The General part and in the relevant regulations of the USaP and $\mathrm{DSaP}$, the final time norm and price for any given moment is determined by multiplying the time and price per product of all the factors used.

$$
\mathrm{K}=\mathrm{K}_{1} \cdot \mathrm{K}_{2} \cdot \mathrm{K}_{3} \cdot \ldots \cdot \mathrm{K}_{n}
$$

There is a table in which the average coefficients are directly written depending on the temperature level and the variant of the group of works. Construction and installation works in USaP for calculation of coefficients were distributed on three groups.

Table 1. The coefficients at the air temperature in the workplace for different groups of work (Groups of work are taken according to USaP)

\begin{tabular}{|c|c|c|c|c|c||}
\hline \multirow{2}{*}{ Groups of work } & \multirow{2}{*}{$\begin{array}{c}\text { Below 0 up } \\
\text { to -10 }\end{array}$} & \multicolumn{4}{|c||}{ Coefficients at a certain temperature in the } \\
& & $\begin{array}{c}\text { Below }-10 \\
\text { up to -20 }\end{array}$ & $\begin{array}{c}\text { Below }-20 \\
\text { up to }\end{array}$ & $\begin{array}{c}\text { Below }-30 \\
\text { up to }\end{array}$ & Below -40 \\
\hline & & & -30 & -40 & \\
\hline I & 1,1 & 1,17 & 1,25 & 1,35 & 1,5 \\
\hline II & 1,15 & 1,3 & 1,45 & 1,6 & 1,75 \\
\hline III & 1,2 & 1,4 & 1,6 & 1,8 & 2 \\
\hline Frozen soil & 1 & 1 & 1,1 & 1,2 & 1,3 \\
\hline
\end{tabular}

The Methodological documentation in construction is no less important document that reflects the estimates on rationing the duration of construction - MDC 12-43.2008

For increasing or decreasing the duration of construction in different regions of Russia, it is necessary to apply correction factors, for example, for the Northern and southern regions numerically equal from 0 to 1,2 .

The guidance document on organizing construction production in the northern zone is also an important document affecting the duration of work.

The overall (annual) impact of lost time due to adverse climatic conditions on the productivity of the specialized construction and installation organization is taken into 
account by the annual downtime factor of workers or machines:

$$
\mathrm{K}_{p}^{g}=\frac{\mathrm{T}_{s} \mathrm{~K}_{s}+\mathrm{T}_{w} \mathrm{~K}_{w}}{\mathrm{~T}}
$$

where $T_{s}, T_{w}-$ duration of this type of work in summer and winter conditions;

$\mathrm{T}$ - the total time period taken for the estimated year;

$$
\begin{aligned}
& \mathrm{K}_{s}=\frac{\mathrm{T}_{s}+\mathrm{T}_{u . s .},}{\mathrm{T}_{s}}, \\
& \mathrm{~K}_{W}=\frac{\mathrm{T}_{w}+\mathrm{T}_{u . w .} .}{\mathrm{T}_{w}},
\end{aligned}
$$

где $\mathrm{K}_{\mathrm{S}}, \mathrm{K}_{\mathrm{W}}$ - factors that take into account the loss of working time due to unfavorable weather conditions in summer and winter;

$\mathrm{T}_{\mathrm{u} . \mathrm{s}}, \mathrm{T}_{\mathrm{u} . \mathrm{w}}$ - the predicted number of days in summer and winter with unfavorable climatic conditions for this type of construction and installation work.

The overall (annual) impact of lost working time due to the decrease in winter labor productivity on the productivity of the specialized construction and installation organization is determined by the influence factor of summer and winter working conditions:

$$
\mathrm{K}_{y}^{g}=\frac{\mathrm{T}_{s}+\mathrm{T}_{w} \mathrm{~K}_{r . w}}{\mathrm{~T}}
$$

where $\mathrm{K}_{\text {r.w }}$ - average coefficient of labor productivity reduction in winter months.

By analyzing the regulatory and technical documentation, it can be seen that the influence of climate factors is only partially indicated. Many additional factors require attention, and to improve the accuracy of scheduling and production schedules, they also need to be taken into account in the calculations.

\section{Results}

For illustration, we will make a scheme of natural and climatic factors.

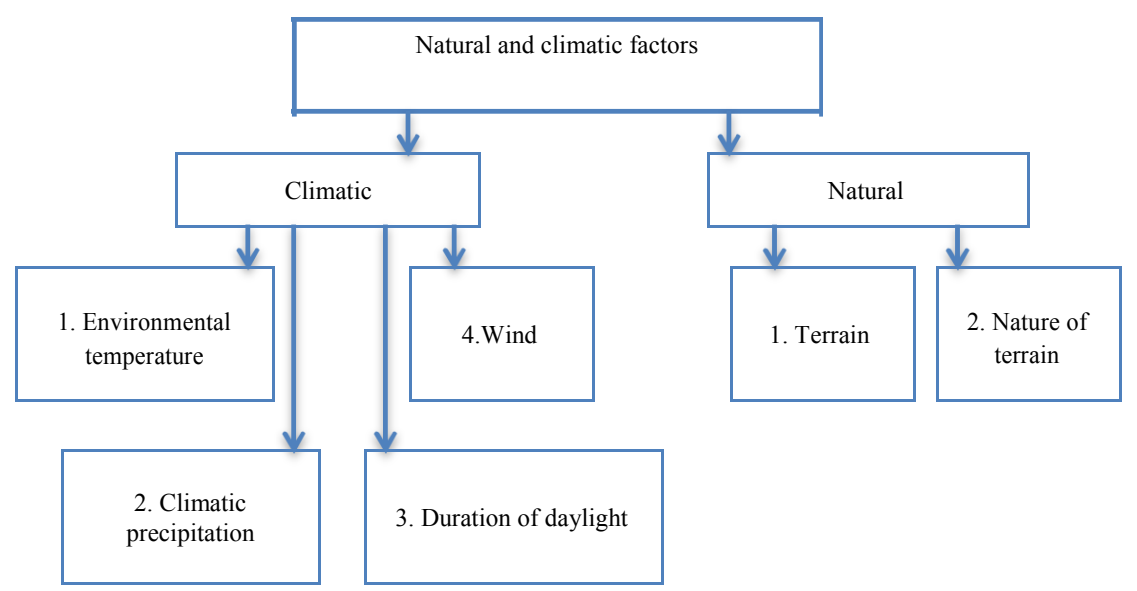

Fig. 1. Systematization of natural and climatic factors

Respectively, according to the scheme, the following groups of factors can be distinguished: climatic (environmental temperature, climatic precipitation, duration of the daylight, wind) and natural (terrain, nature of the terrain). These factors have an impact on the productivity of construction work. The definition of this parameter is given in the 
regulatory and technical documents.

In foreign construction, architectural climatography is used to compile climatic characteristics. It is based on a comprehensive evaluation of climate factors that directly affect a person in a particular architectural environment. Factors are considered separately and in aggregate (temperature and humidity, reduced temperature and wind, high temperature and solar radiation) $[1,2,3]$.

In the construction work, the influence of natural and climatic factors can be considered on the following example. Let's consider the execution of facade works with the use of front lifts.

In hot climates, at high temperatures, for example, when the air temperature reaches 30 $40^{\circ}$, the production of work becomes more complicated. The person gets tired faster, it is necessary to make frequent breaks. At negative temperatures it is difficult to do the job, because a person wears warm clothes, this makes his movement difficult. All these factors influence on labor intensity. The front lifts lose stability when the wind load is applied. With heavy precipitation, visibility decreases and work becomes more complicated, therefore the time for its implementation increases (see pict.2) [4,5].

When building skyscrapers, in the city of Moscow, there are many difficulties. One of them is the execution of facade works. In very windy months, it is impossible to make facade works due to strong wind. The glazing elements cannot be raised to the desired height. It is necessary to take into account the aerodynamic effects occurring around highrise buildings, including the formation of centers of convergence of vertical air flows around high-rise buildings on the basis of temperature convection. This leads to a shift in the construction period and a large financial cost [6-10].

The construction of large objects in mountainous conditions is greatly influenced by natural factors. The technique is very difficult to choose. Some technique cannot be started in mountainous conditions because it is not intended to work at such atmospheric pressure. The mixer trucks should be filled only half. It is very difficult to drive on roads, they are very narrow and winding. These factors complicate the production of works and slow down the stages of construction (pict.3) [11].

Also an example of complex geological conditions is the Arctic zone of Russia, which can be basic also for mining and construction activities. The presence of thickness of perennial frozen rocks makes it necessary to define special requirements, both for applied geotechnical logic and for mountain equipment $[1,6]$.

One can face a problem such as the need to change the river bed. The change of the river bed is required to establish a temporary road, a pipeline or a tunnel. For example, the river was shifted by 100 meters, it flowed in another way. Everything turned out, everything is good, the construction is going. But in a few months, due to heavy precipitation, the river can break through the platinum and return to the old channel. As a result, all the equipment isflooded, all the roads are flooded. The construction stopped until an unknown time. The construction dates have moved. The equipment had to be written off and the organization incurred huge financial costs. 


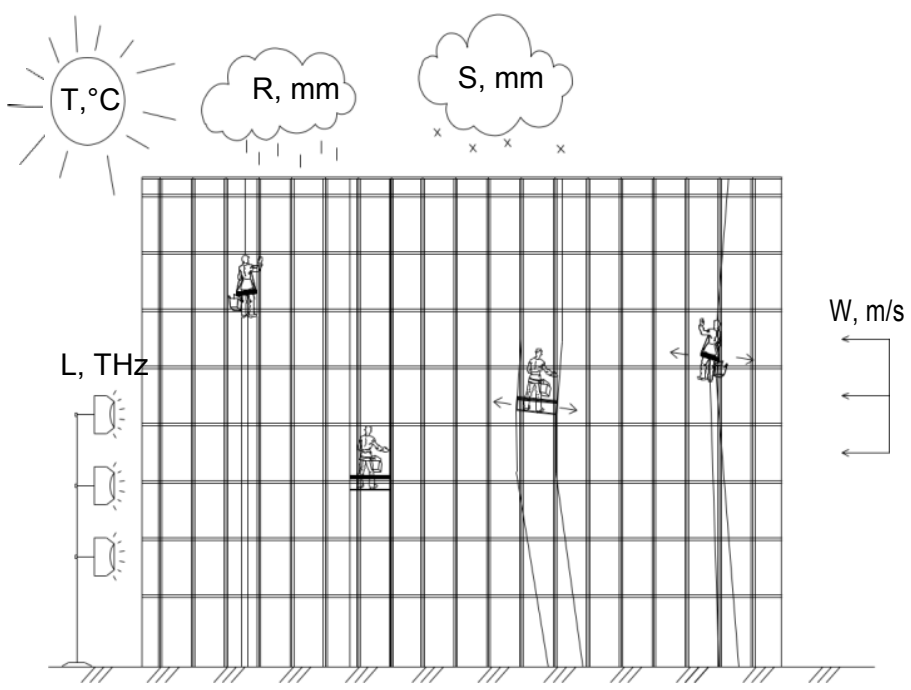

Fig. 2. Influence of climatic factors on the organization of construction production

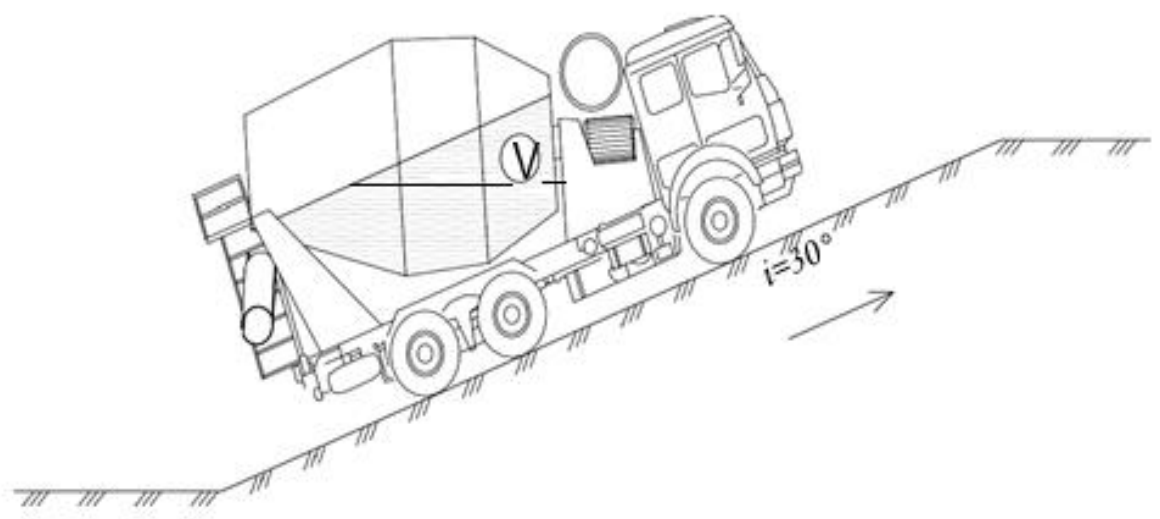

Fig. 3. Influence of natural factors on the organization of construction production

Table 2. Factors of influence on the organization of construction (0-Does not influence; 1-Slight influence; 2-Significant influence).

\begin{tabular}{|c|c|c|c|c|c|c|c|}
\hline \multirow{2}{*}{$№$} & Types of work & \multicolumn{7}{|c|}{$\begin{array}{c}\text { Influence factors } \\
\text { temperature }\end{array}$} & $\begin{array}{c}\text { Environment } \\
\text { precipitation }\end{array}$ & $\begin{array}{c}\text { Duration } \\
\text { of the day }\end{array}$ & $\begin{array}{c}\text { Lie of the } \\
\text { ground }\end{array}$ & Terrain & $\begin{array}{c}\text { The nature } \\
\text { of the terrain }\end{array}$ \\
\hline 1. & Preparatory work & 1 & 1 & 1 & 1 & 2 & 2 \\
\hline 2. & Excavations & 2 & 2 & 1 & 0 & 2 & 0 \\
\hline 3. & $\begin{array}{c}\text { Installation of } \\
\text { monolithic structures }\end{array}$ & 2 & 2 & 1 & 2 & 2 & 0 \\
\hline 4. & $\begin{array}{c}\text { Installation of precast } \\
\text { concrete structures }\end{array}$ & 2 & 2 & 1 & 0 & 2 & 0 \\
\hline 5. & Facade work & 2 & 2 & 2 & 2 & 0 & 0 \\
\hline 6. & Interior finishing & 2 & 1 & 0 & 0 & 0 & 0 \\
\hline 7. & Roofing work & 1 & 2 & 2 & 2 & 0 & 0 \\
\hline
\end{tabular}




\subsection{Preparatory work}

The factor that complicates this process is terrain. It can be plain, hilly or mountainous terrain. Such conditions make it difficult to transport the necessary material to construction sites, accessible generally used transport is not always suitable for this type of terrain, which affects the duration of the work. There are also additional costs in the production of works, due to the unfavorable nature of the terrain, which has a great influence on construction. Because the work is under way in a 24-hour schedule, there is a need for additional lighting at night, which is a requirement for the quality of work, but at the same time causes the corresponding additional costs $[12,13]$.

\subsection{Excavations}

At sub-zero temperatures, work becomes very complicated, the labor intensity increases repeatedly. Special methods for soil development are required. So, for example, while digging pits and trenches, soil should be warmed after its development. While working in a well-prepared field, earthmoving machinery must be operated 24 hours a day to prevent ground from becoming frozen during breaks in work. The foundation of the pits and trenches should be protected from frost by a shortage of soil to the design mark. In the soil intended to fill the grooves of the pits and trenches, the number of frozen lumps should not exceed $15 \%$ of the total volume. When developing soil in winter time, it is necessary to carry out preliminary measures to prevent freezing of the soil, covering the spot of the pit with thermal material. In case of development of frozen ground firstly it is necessary to loosen it or to heat with tubular electric heater or heat generators. The bottom of the pit must be protected from freezing. With the presence of rain or snow, excavation work becomes more complicated, as it is difficult for the technique to drive on the site. Duration of the day does not influence on excavation, at night time the process becomes more complicated, as it is necessary to use additional lighting. In case of complex relief, the execution of the site layout also changes; it is realized on the leveling grid of squares additionally divided by diagonal to triangles. It allows monitoring variations of a specific relief more accurately and qualitatively [13].

\subsection{Installation of monolithic structures}

Firstly, reducing the ambient temperature significantly slows down the process of durability of concrete increasing. In case of negative temperature, before laying the concrete mixture, it is necessary to clean the concrete from snow and ice formwork and the place of delivery of concrete. Non-decked surfaces of structures should be covered with steam- and heatinsulating materials immediately after the finishing of concreting. Releases of fittings of concreted structures should be covered or insulated to a height of at least $0.5 \mathrm{~m}$. In case of climatic precipitation, the process of the construction of monolithic structures becomes more complicated, because with heavy atmospheric precipitation (snowfalls, showers), concrete placement should be made in pre-made canvas tents or in light enclosures. Duration of a day practically does not influence on installation of monolithic structures, in night time the process becomes more complicated, as it is necessary to install additional lighting. Movement and installation works of vertical panels and similar structures with a large sailing capacity should be stopped at a wind speed of $10 \mathrm{~m} / \mathrm{s}$ or more.

\subsection{Installation of precast concrete structures [14]}

The process of work in winter isn't almost different from the summer period, but the 
condition must be observed - to heat the jointing surfaces to a positive temperature of $+5 \ldots 8{ }^{\circ} \mathrm{C}$ Prefabricated reinforced concrete elements during transportation and storage in the warehouse must be protected from rain and snow; installation is also permitted only to be served with dirt-free and heated until the complete disappearance of icings. One must not perform installation work at an open height at a wind speed of $15 \mathrm{~m} / \mathrm{s}$ or more, at icy condition, thunderstorms or fog that exclude visibility within the front of the work. The process of developing the crane's motion plan during installation and the order of installation of structures due to the constrained conditions of the complex relief is complicated [15].

\subsection{Facade works}

It is not allowed to paint facades at an air temperature in the shade $+27{ }^{\circ} \mathrm{C}$ and above; priming, filler, plaster work and painting facades can't be made at temperature below +5 ${ }^{\circ} \mathrm{C}$; It is not allowed to paint facades during rain or on a damp facade after rain. The duration of daylight significantly influences on the facade work, as many small elements require concentration of attention. While laying or facing the outer walls of multistory buildings, it is forbidden to work during thunderstorm, snowfall, fog that exclude visibility within the front of the work, or at a wind speed of more than $15 \mathrm{~m} / \mathrm{s}$. It is not allowed to paint facades in wind speed exceeding $10 \mathrm{~m}$ per second.

\subsection{Finishing work}

Inside finishing work should be done after completing the roof, walls and partitions. At the beginning of finishing works the building should be prepared: to glaze the bindings and to close all openings. Finishing works are carried out in parallel with sanitary-technical, electrical installation and general construction works in strict compliance with safety regulations. The final finishing of the premises should only be performed after the completion of installation of the equipment systems. Plaster work should be performed at a positive ambient temperature and separated surfaces not less than $10^{\circ} \mathrm{C}$ and humidity of air not more than $60 \%$.

\subsection{Roofing work}

Roofing works are usually performed at an air temperature of +30 to $-20^{\circ} \mathrm{C}$. Work in rainy and windy conditions, snowy and icy conditions without special coverings is not carried out (during precipitation, work has to be suspended or to equip canopies over all building constructions). The duration of the daylight significantly influence on the facade work as many small elements require concentration of attention. It is not allowed to perform roofing works during icy, foggy conditions, excluding visibility within the front of works, thunderstorms and wind at a speed of $15 \mathrm{~m} / \mathrm{s}$ or more [16].

\section{Discussion}

Significance of the question is very important, the results can be used in development of regulatory and technical documentation in the field of construction production organization.

Under modern conditions of development of organizational and technical documentation, issues related to the consideration of natural factors are not fully considered, and therefore there are large changes in the development and adjustment of documentation. 
The analysis of the conditions of work shows that there are certain periods of construction. Favorable and unfavorable for every different kind of work. These should be taken into account in the planning of the calendar. The executors, as well as the engineering and technical workers, must control the compliance of the projected parameters (conditions) of performance of work to the current conditions. For example, in the project of production of works in the execution of monolithic works, temperature should vary from $0{ }^{\circ} \mathrm{C}$ to $10^{\circ} \mathrm{C}$. But, in reality, winter is cold; the temperature has fallen and does not correspond to the projected. In such case, appropriate action should be taken. Accordingly, it must always be monitored. The contractors, as well as the engineers and technicians, should monitor the parameters that were laid down in the project of production of works with real conditions. If they do, it is normal, if they don't, one should take any measures to reduce the influence of the factors.

The territory of Russia is divided into seven climatic zones, in which economic activity is carried out and in which infrastructure facilities are created in the industrial and social spheres. This issue is especially relevant for construction organizations, which perform construction work in various climatic conditions. "Donstroy", "Monarch". These organizations perform construction and installation works throughout Russia [12,17-19].

\section{Conclusion}

1. As a result of the analysis of regulatory technical and scientific literature, one established that the existing documents and recommendations do not fully and comprehensively consider the impact of natural and climatic conditions on construction production.

2. The labor intensity of construction works is calculated everywhere from the production of works in standard (normal) conditions. But often the working conditions differ from the planned ones.

3. In design of construction production, it is necessary to take into account the influence of these factors both in the performance of certain types of work, and in determining the estimated duration of construction as a whole.

4. In development of calendar plans for construction and work schedules, favorable and unfavorable periods of work performance according to the calendar days and climate diagram of the construction area should be considered.

\section{References}

1. K.V. Kurguzov, I.K. Fomenko, Spatial and correlation analysis of engineeringgeological survey data for logistics center construction, DOI:10.22227/19970935.2019.8.954-966

2. M. Grosso, G. Chiesa, M. Nigra, Heritage and Technology. Mind Knowledge Experience, XIII International Forum Le vie deiMercanti (LaScuoladiPitagoraeditrice, 2015).

3. T.R. Oke, G. Mills, A. Christen, J.A. Voogt, Urban climates (Cambridge University Press, 2017). DOI:10.1017/9781139016476

4. G. Chiesa, M.A. Grosso, Sustainable Building for a Cleaner Environment, 115-129 (2019). DOI: 10.1007/978-3-319-94595-8_11 
5. M. Grosso, G. Chiesa, M. Nigra, Heritage and Technology. Mind Knowledge Experience, XIII Inter- national Forum Le vie dei Mercanti, 1572-1581 (La Scuola di Pitagora editrice Publ., 2015).

6. S. Saydam, V. Kecojevic, Transactions of the Institutions of Mining and Metallurgy, Section A: Mining Technology, 123(1) (2014).

7. I.V. Dunichkin, O.I. Poddaeva, K.S. Golokhvast, Building Simulation, 12(2), 177-182 (2019). DOI: 10.1007/s12273-018-0495-Z

8. V.V. Kotelnikov, N.P. Chetverikov, R.A. Andrievsky, A.A. Ananiev, Safety of construction and implementation of the construction control (Method. benefit. Moscow: JSC "Scientific and technical center "Industrial safety", 2012).

9. V.N. Burkov, I.V. Burkova, R. Barkhi, M. Berlinov, MATEC Web of Conferences, 251, 06027 (2018). DOI: https://doi.org/10.1051/matecconf/201825106027.

10. N. Antoniou, H. Montazeri, H. Wigo, M.K.A. Neophytou, B. Blocken, M. Sandberg, Building and Environment, 126, 355-372 (2017). DOI: 10.1016/j.buildenv.2017.10.013

11. A.Z. Vartanov, Yu.P. Galchenko, G.V. Kalabin, I.V. Petrov, A.V. Fedas, Rationale for the paradigm of developmentof geotechnology and mining equipment that provide for mining and construction activitiesn the arctic, DOI:10.22227/1997-0935.2018.2.240248

12. .V.G. Borkovskaya, D. Passmore, Smart Technologies and Innovations in Design for Control of Technological Processes and Objects: Economy and Production, 24, FarEastCon 2018, SIST 138.(2018). DOI:10.1007/978-3-030-15577-3_24

13. V. Telichenko, V. Rimshin, V. Eremeev, V. Kurbatov, MATEC Web of Conferences, 196, 02025 (2018)

14. V.F. Kas'yanov, V. Danilchenko, V. Amelin, V. Tolmachev, MATEC Web of Conferences, 251, 06030 (2018). DOI: 10.1051/matecconf/201825106030.

15. A. Ricci, I.M. Kalkman, B. Blocken, M.P. Repet- to, M. Burlando, A. Freda, PHYSMOD 2015 - International Workshops on Physical Modeling of Flow and Dispersion Phenomena, Empa Dübendorf and ETH Zürich, Switzerland, 7-9 (2015).

16. V.G. Borkovskaya, Advanced Materials Research, 945-949, Chapter 22: Manufacturing Management and Engineering Management, 3012- 3015 (2014). DOI: 10.4028/www.scientific.net/AMR.945-949.3012.

17. V. Evseev, R.. Barkhi, A. Pleshivtsev, A. Scrynnik, Modeling the Influence of Weather and Climatic Conditions on the Safety Characteristics of the Construction Process, DOI:10.1051/e3sconf/20199703035

18. V.G. Borkovskaya, Applied Mechanics and Materials, 475- 476, Chapter 15: Engineering Management. December, 1703-1706 (2013). DOI: 10.4028/www.scientific.net/AMM.475-476.1703.

19. . V.G. Borkovskaya, Applied Mechanics and Materials, 467, Materials Science and Mechanical Engineering. Chapter 2: Building Materials and Construction Technologies, 287-290 (2013). DOI: 10.4028/www.scientific.net/AMM.467.287. 